\title{
Keefektifan Cendawan Metarhizium brunneum Petch Pada Hama Rayap Perusak Tanaman Pala Di Laboratorium
}

(The Effectiveness Of Metarhizium brunneum Petch Fungi In Termite Pest Plant Destroyer Nutmeg In The Laboratory)

\author{
Muhammad Rezza Fahlevi ${ }^{1}$, Muhammad Sayuthi ${ }^{1}$, Alfian Rusdy ${ }^{1}$ \\ ${ }^{1}$ Program Studi Agroteknologi, Fakultas Pertanian, Universitas Syiah Kuala \\ Darussalam - Banda Aceh \\ Email: revi_007@yahoo.com
}

\begin{abstract}
Abstrak. Penelitian ini bertujuan untuk mengetahui waktu kematian rayap setelah diinfeksi oleh cendawan M. brunneum sebagai biotermitisida di Laboratorium serta untuk mendapatkan konsentrasi yang efektif dari cendawan entomopatogen M. brunneum dalam mengendalikan hama rayap pada tanaman pala. Penelitian dilakukan di Laboratorium Hama dan Lamoratorium Penyakit Tumbuhan Fakultas Pertanian Universitas Syiah Kuala mulai dari bulan September 2015 sampai Februari 2016. Penelitian ini menggunakan Rancangan Acak Lengkap (RAL) non faktorial yang terdiri atas 6 taraf perlakuan dengan 4 ulangan sehingga terdapat 24 satuan percobaan. Berdasarkan hasil penelitian didapatkan bahwa mortalitas $C$. curvignathus tertinggi dijumpai pada aplikasi $10^{10}$ konidia/9 ml aquades dan $10^{6}$ konidia/9 $\mathrm{ml}$ aquades yaitu $100 \%$ dengan masa inkubasi $M$. brunneum mulai tampak pada 1,83 hari setelah aplikasi pada perlakuan $10^{10}$ konidia/9 ml aquades dan mampu menghambat kemampuan makan rayap hingga 50,77\%. Rata-rata waktu kematian C. curvignathus mencapai 100\% kurang dari 4 hari setelah aplikasi
\end{abstract}

Kata kunci : C. curvignathus, M. brunneum, tanaman pala, Biotermitisida.

\begin{abstract}
This research aims to know the time of the death of termites after infection by fungi $M$. brunneum as biotermitiside in the laboratory as well as to get an effective concentration of verticillium M. brunneum in termite pest control at the plant. Research done in the laboratory of pest and plant disease laboratory of the Faculty of Agriculture University of Syiah Kuala starting from September 2015 Fund February 2016. This study used a Randomized Complete Design (RAL) non factorial of 6 degrees of treatment with 4 repeats so there are 24 units of the experiment. Based on the research results obtained that the mortality of $C$. curvignathus highest $10^{10}$ application found at conidia/ $9 \mathrm{ml}$ aquadest and conidia $10^{6} / 9 \mathrm{ml}$ aquadest $100 \%$ valid with an incubation period of $M$. brunneum began looking at 1.83 days after application at the treatment conidia $10^{10} / 9 \mathrm{ml}$ aquadest and capable of inhibiting the ability to eat termites to 50,77\%. The average time of death C. curvignathus achieve $100 \%$ less than 4 days after application
\end{abstract}

Keywords: C. curvignathus, M. brunneum, nutmeg plants, Biotermitiside.

\section{PENDAHULUAN}

Tanaman pala (Myristica fragrans Houtt ) merupakan tanaman asli Indonesia, karena tanaman ini berasal dari Maluku. Tanaman pala menyebar ke Pulau Jawa, pada saat perjalanan Marcopollo ke Tiongkok yang melewati pulau

Coresponding author: revi_007@yahoo.com 
Jawa pada tahun 1271 sampai 1295 pembudidayaan tanaman pala terus meluas sampai Sumatera. Dunia mengenal Maluku dari hasil pala dan cengkeh (Bustaman, 2007).

Namun pada saat ini telah timbul permasalahan terhadap budidaya tanaman pala yang salah satunya adalah gangguan hama rayap yang merugikan secara ekonomis dan belum ditemukan teknik pengendaliannya secara tepat.

Rayap subteran Coptotermes curvignathus merupakan jenis yang paling sukses hidup di lingkungan perkebunan hingga perkotaan. Serangga ini dapat membentuk koloni dalam jumlah yang besar dan memiliki wilayah jelajah yang tinggi. Dalam koloni C.curvignathus dapat dijumpai lebih dari satu juta individu dengan wilayah jelajah sekurang-kurangnya $450 \mathrm{~m} 2$ (Nandika, et al., 2003).

Serangan rayap pada tanaman pala merupakan salah satu kendala utama yang perlu ditanggulangi. Serangan hama ini dapat menimbulkan kerusakan fisik secara langsung pada tanaman yang berdampak negatif pada hasil produksi. Akibat serangan rayap juga menyebabkan perlukaan pada bagian akar tanaman yang dapat menghambat translokasi air dan zat hara dari tanah terganggu dan akhirnya tanaman mati (Nandika et al., 2003). Berdasarkan hal tersebut, tidak mengherankan apabila dibandingkan dengan jenis rayap lainnya, rayap $C$. curvignathus lebih berbahaya menyerang perkebunan serta bangunan gedung.

Selama ini pengendalian rayap dilakukan dengan menggunakan insektisida sintetis dengan dosis dan konsentrasi yang tidak sesuai anjuran dan berdampak negatif terhadap lingkungan. Pemanfaatan bahan kimia seperti organochlorine sangat efektif untuk pengendalian rayap namun membahayakan kesehatan manusia dan lingkungan. Persistensinya yang bertahan lama di lingkungan menyebabkan jenis pestisida ini masuk ke dalam rantai makanan manusia. Untuk mengatasi masalah tersebut maka perlu dilakukan pengendalian dengan cara lainnya seperti pemanfaatan cendawan entomopatogen Metarhizium spp. yang dapat digunakan untuk mengendalikan berbagai jenis hama dari berbagai ordo seperti Lepidoptera, Coleoptera, Isoptera serta Hemiptera (Prayogo, 2006).

Cendawan entomopatogen Metarhizium spp. memiliki kemampuan untuk menempel dan menembus kutikula inang dan tumbuh ke bagian internal tubuh inang sebagai nutrisi untuk pertumbuhan yang mengakibatkan kematian inang. Kemudian cendawan tersebut juga dapat menghancurkan jaringan lain dengan melepaskan toksin dan akan mempengaruhi perkembangan inang secara normal. Beberapa jenis toksin yang dihasilkan oleh Metarhizium spp terhadap serangga yaitu: cytohalasins, destruxin dan swainsonine. Senyawa-senyawa tersebut dapat menyebabkan kelainan fungsi lambung serta merusak jaringan otot rayap (Sayuthi et al., 2013). Menurut Sayuthi et al,. (2013), pemanfaatan agen hayati cendawan $M$. brunneum di laboratorium, hasilnya efektif sebagai agen hayati untuk mematikan hama rayap dibandingkan dengan spesies $M$. anisopliae dan B.bassiana.

Menurut (Desyanti, 2007) tingkat sporulasi cendawan $M$. brunneum pada tubuh rayap Coptotermes carvignatus pada kerapatan konidia 106/ml adalah 74\%. Penggunaan $10 \%$ rayap terinfeksi (carrier) yang diinokulasi dengan cendawan ini

Coresponding author: revi_007@yahoo.com 
$(1,21 \times 106 / \mathrm{mL})$ selama 15 hari menyebabkan mortalitas $C$. gestroi lebih dari 90\%. Selanjutnya hasil penelitian dengan aplikasi cendawan M. brunneum dengan kerapatan konidia $106 / \mathrm{mL}$ dan $108 / \mathrm{mL}$ menyebabkan mortalitas Cylas formicarius sebanyak $50 \%$ dan $82.50 \%$ pada 10 HSA (Faishol, 2011).

Berdasarkan pertimbangan tersebut maka perlu diteliti tentang patogenisitas cendawan entomopatogen $M$. brunneum terhadap hama rayap yang merusak tanaman pala dengan harapan dapat memberikan sumbangan informasi tentang teknologi alternatif pengendalian rayap yang ramah lingkungan. Tujuan penelitian ini adalah untuk mengetahui waktu kematian rayap setelah diinfeksi oleh cendawan $M$. brunneum sebagai biotermitisida di Laboratorium serta untuk mendapatkan konsentrasi yang efektif dari cendawan entomopatogen $M$. brunneum dalam mengendalikan hama rayap pada tanaman pala.

\section{METODE PENELITIAN}

Penelitian ini dilaksanakan di Laboratorium Hama Tumbuhan dan Laboratorium Penyakit Tumbuhan Program Studi Proteksi Tanaman Fakultas Pertanian Universitas Syiah Kuala. Pada penelitian ini digunakan rancangan acak lengkap (RAL) non faktorial yang terdiri atas 6 taraf perlakuan dengan 4 ulangan sehingga terdapat 24 satuan percobaan. Kerapatan yang digunakan adalah $0,10^{2}$, $10^{4}, 10^{6}, 10^{8}$ dan $10^{10}$ konidia/9 $\mathrm{ml}$ aquades.

\section{Pelaksanaan Penelitian}

Pelaksanaan penelitian dimulai dengan pembuatan media PDA untuk perbanyakan isolat cendawan $M$. brunneum yang kemudian digunakan dalam penelitian. Selanjutnya proses revirulensi rayap $C$. curvignathus yang bertujuan untuk meningkatkan daya infeksi cendawan ke rayap uji. Selanjutnya dilakukan identifikasi jenis rayap agar dapat mengetahui bioekologi rayap uji dan mempermudah dalam pengendalian. Tahap terakhir adalah pengaplikasian cendawan $\mathrm{M}$. brunneum pada rayap $C$. curvignathus dengan cara mencelupkan rayap pada suspensi cendawan sesuai perlakuan yang di uji.

Pengamatan yang dilakukan terdiri dari pengujian daya kecambah (viabilitas spora) untuk mengetahui persentase tingkat perkecambahan spora yang akan diuji. Pengamatan mortalitas dilakukan mulai dari sehari setelah aplikasi sampai ada unit percobaan yang mati $80 \%$. Pengamatan rata-rata waktu kematian dilakukan dengan interval waktu 1 hari setelah aplikasi sampai ada unit percobaan yang mati $100 \%$. Pengamatan persentase penghambat makan dilakukan dengan cara menimbang umpan sebelum dan sesudah penelitian yang bertujuan untuk membandingkan tingkat kemampuan makan rayap yang telah di aplikasikan $M$. brunneum sesuai dengan perlakuan yang diuji.

Coresponding author: revi_007@yahoo.com 


\section{HASIL DAN PEMBAHASAN}

\section{Persentase Perkecambahan (Viabilitas Spora)}

Cendawan $M$. brunneum telah diuji tingkat virulensinya lalu diuji daya kecambahnya dengan cara mengambil 4 sampel mulai 24, 30 dan 36 jam setelah inokulasi dengan menggunakan haemocytometer. Data yang diperoleh berturutturut 24 JSI yaitu $73,70,75,87,80,43,92,39 \%$ kemudian pada pengamatan 30 JSI yaitu $81,74,80,43,89,13$ dan $91,96 \%$ dan pada pengamatan 36 JSI yaitu 93,48, 96,96, 96,30 dan 98,91\%. Rata-rata persentase daya kecambah (viabilitas spora) M. brunneum dapat dilihat pada Tabel 1 berikut ini.

Tabel 1. Rata-rata viabilitas spora $M$. brunneum pada pengamatan 24, 30 dan36 jam setelah inokulasi (JSI).

\begin{tabular}{cc}
\hline Waktu Pengamatan & Viabilitas Spora (\%) \\
\hline 24 Jam & 80,60 \\
30 Jam & 85,82 \\
36 Jam & 96,41 \\
\hline
\end{tabular}

Berdasarkan Tabel 1 di atas menunjukkan bahwa, rata-rata viabilitas spora pada pengamatan 24, 30, dan 36 JSI berada diatas $80 \%$. Hal ini membuktikan bahwa isolat cendawan M. brunneum berpotensi untuk dijadikan bioinsektisida, karena persentase perkecambahannya di Laboratorium sudah optimal. Sesuai dengan hasil penelitian (Trizelia, 2005) yang menyatakan bahwa isolat yang memiliki daya kecambah konidia yang tinggi akan mempunyai peluang yang besar untuk bisa menimbulkan infeksi dan mematikan serangga uji. Contoh isolat Bb-La2 dari B. bassiana yang daya kecambahnya mencapai 97,25 $\pm 2,22 \%$.

Selanjutnya (Hatzipapas et al., 2002 dalam Trizelia 2005) menambahkan bahwa, perkecambahan konidia sangat tergantung pada kondisi lingkungan seperti kelembaban, suhu, cahaya serta nutrisi. (Junianto \& Sukamto 1995 dalam Trizelia 2005) menyatakan bahwa konidia dinyatakan berkecambah apabila panjang tabung tabung kecambah telah melebihi diameter konidia atau panjangnya lebih dari $3 \mu \mathrm{m}$.

Menurut Desyanti et al., (2007) evaluasi daya kecambah konidia cendawan entomopatogen perlu dilakukan terutama apabila cendawan tersebut akan dikembangkan sebagai bioinsektisida. Daya kecambah konidia merupakan salah satu kriteria dalam pemilihan isolat; cendawan yang memiliki daya kecambah konidia di atas $80 \%$ telah memenuhi syarat untuk dikembangkan sebagai bioinsektisida. Selanjutnyadinyatakan bahwa dalam pemilihan isolat yang akan digunakan, kecepatan perkecambahan juga harus diperhitungkan. Isolat yang

Coresponding author: revi_007@yahoo.com 198 
berkecambah lebih cepat lebih berpotensi untuk menimbulkan infeksi, karena isolat ini dapat terhindar dari pengaruh kekeringan, pengaruh dari mikroorganisme lain dan terlepas dari kutikula serangga pada waktu ekdisis.

\section{Mortalitas Rayap C. curvignathus}

Hasil pengamatan terhadap mortalitas rayap yang diamati pada 1-5 HSA dapat dilihat pada Tabel 2. Hasil analis ragam menunjukkan bahwa mortalitas rayap berbeda sangat nyata akibat aplikasi cendawan $M$. brunneum

Tabel 2. Rata-rata mortalitas rayap $C$. curvignathus akibat aplikasi cendawan M. brunneum pada 1-5 HSA.

\begin{tabular}{|c|c|c|c|c|c|}
\hline \multirow{2}{*}{$\begin{array}{c}\text { Kerapatan } \\
\text { Konidia/mL } \\
\text { Aquades }\end{array}$} & \multicolumn{5}{|c|}{ Mortalitas Rayap C. curvignathus (\%) } \\
\hline & 1 HSA & 2 HSA & 3 HSA & 4 HSA & 5 HSA \\
\hline K0 (Kontrol) & $\begin{array}{c}0,00 \\
(0,91) \mathrm{a}\end{array}$ & $\begin{array}{c}0,00 \\
(0,91) \mathrm{a}\end{array}$ & $\begin{array}{c}0,00 \\
(0,91) \mathrm{a}\end{array}$ & $\begin{array}{c}0,00 \\
(0,91) \mathrm{a}\end{array}$ & $\begin{array}{c}12,50 \\
(18,12) \mathrm{a}\end{array}$ \\
\hline $\mathrm{K} 1\left(10^{2}\right)$ & $\begin{array}{c}10,00 \\
(16,08) \mathrm{ab}\end{array}$ & $\begin{array}{c}37,50 \\
(36,92) b\end{array}$ & $\begin{array}{c}47,50 \\
(43,49) \text { bc }\end{array}$ & $\begin{array}{c}60,00 \\
(50,83) b c\end{array}$ & $\begin{array}{c}80,00 \\
(63,43) b\end{array}$ \\
\hline $\mathrm{K} 2\left(10^{4}\right)$ & $\begin{array}{c}30,00 \\
(33,05) \text { bc }\end{array}$ & $\begin{array}{c}62,50 \\
(53,15) b\end{array}$ & $\begin{array}{c}82,50 \\
(71,44) \mathrm{cd}\end{array}$ & $\begin{array}{c}95,00 \\
(80.33) \mathrm{d}\end{array}$ & $\begin{array}{c}97,50 \\
(84,71) \mathrm{c}\end{array}$ \\
\hline $\mathrm{K} 3\left(10^{6}\right)$ & $\begin{array}{c}27,50 \\
(30,87) b c\end{array}$ & $\begin{array}{c}50,00 \\
(45,00) b\end{array}$ & $\begin{array}{c}62,50 \\
(52,56) b c\end{array}$ & $\begin{array}{c}75,00 \\
(60,86) b c\end{array}$ & $\begin{array}{c}100,00 \\
(89,09) \mathrm{c}\end{array}$ \\
\hline $\mathrm{K} 4\left(10^{8}\right)$ & $\begin{array}{c}25,00 \\
(26,20) b c\end{array}$ & $\begin{array}{c}52,50 \\
(50,13) b\end{array}$ & $\begin{array}{c}75,00 \\
(63,58) \mathrm{cd}\end{array}$ & $\begin{array}{c}85,00 \\
(70,22) \mathrm{cd}\end{array}$ & $\begin{array}{c}95,00 \\
(80,33) \mathrm{c}\end{array}$ \\
\hline $\mathrm{K} 5\left(10^{10}\right)$ & $\begin{array}{c}42,50 \\
(40,61) \mathrm{c}\end{array}$ & $\begin{array}{c}65,00 \\
(57,75) b\end{array}$ & $\begin{array}{c}92,50 \\
(75,95) \mathrm{d}\end{array}$ & $\begin{array}{c}92,50 \\
(75,95) \mathrm{d}\end{array}$ & $\begin{array}{c}100,00 \\
(89,09) \mathrm{c}\end{array}$ \\
\hline BNT 0,05 & 17,01 & 25,02 & 19,24 & 13,88 & 10,94 \\
\hline
\end{tabular}

Tabel 2 menunjukkan bahwa, rata-rata mortalitas rayap C. curvignathus akibat aplikasi cendawan M. brunneum pada pengamatan 1-5 HSA secara umum ada perbedaan yang nyata antara perlakuan dengan kontrol. Rata-rata mortalitas tertinggi pada 5 HSA yaitu pada perlakuan K5 $\left(10^{10}\right)$ yaitu mencaapai $100 \%$ yang tidak berbeda nyata dengan perlakuan $\mathrm{K} 2$ dan $\mathrm{K} 4$, dan mortalitas terendah dari keseluruhan pengamatan terdapat pada perlakuan K0 yang hanya mencapai $12,50 \%$ pada 5 HSA. Tinggi rendahnya mortlitas rayap sangat dipengaruhi oleh kerapatan konidia, karena kemungkinan besar semakin banyak jumlah konidia semakin banyak pula senyawa metabolik sekunder yang dikeluarkan. Contohnya senyawa destruxin cytohalasins, swainsonine. Sesuai dengan pendapat (Desyanti, 2007., Boucias \& Pendland, 1998 dalam Sayuthi, 2012), yang menyatakan bahwa cendawan $M$. brunneum mempunyai kemampuan untuk menempel dan menembus kutikula inang dan tumbuh ke bagian internal tubuh inang (hemocoel) sebagai sumber nutrisi untuk pertumbuhan yang mengakibatkan kematian inang. 
Kemudian cendawan tersebut juga dapat menghancurkan jaringan lain denganmelepaskan toksin dan akan mempengaruhi perkembangan inang secara normal.

\section{Rata-rata Waktu Kematian Rayap C. curvignathus}

Hasil pengamatan terhadap rata-rata waktu kematian rayap $C$. curvignathus dapat dilihat pada Tabel 3. Hasil analisis ragam menunjukkan bahwa aplikasi $M$. brunneum berpengaruh nyata terhadap waktu kematian rayap.

Tabel 3. Rata-rata waktu kematian rayap C. curvignathus akibat aplikasi M. brunneum.

\begin{tabular}{cc}
\hline Kerapatan Konidia/mL Aquades & Waktu kematian rayap (hari) \\
\hline $\mathrm{K} 1\left(10^{2}\right)$ & $3,55 \mathrm{~b}$ \\
$\mathrm{~K} 2\left(10^{4}\right)$ & $2,20 \mathrm{a}$ \\
$\mathrm{K} 3\left(10^{6}\right)$ & $2,68 \mathrm{ab}$ \\
$\mathrm{K} 4\left(10^{8}\right)$ & $2,58 \mathrm{ab}$ \\
$\mathrm{K} 5\left(10^{10}\right)$ & $1,88 \mathrm{a}$ \\
& \\
\hline BNT 0,05 & $\mathbf{0 , 9 8}$ \\
\hline
\end{tabular}

Tabel 3 menunjukkan bahwa aplikasi cendawan M. brunneum pada rayap C. curvignathus ada perbedaan yang nyata antara perlakuan K1 $\left(10^{2}\right)$ dengan perlakuan K2 $\left(10^{4}\right)$ dan K5 $\left(10^{10}\right)$ dan tidak berbeda nyata dengan perlakuan K3 $\left(10^{6}\right)$ dan K4 $\left(10^{8}\right)$. Rata-rata waktu kematian tercepat pada perlakuan K5 $\left(10^{10}\right)$ yaitu pada 1,88 hari sedangkan terlama pada perlakuan $\mathrm{K} 1\left(10^{2}\right)$ yaitu pada 3,55 hari. Hal ini disebabkan perbedaan jumlah konidia dari setiap perlakuan, semakin banyak jumlah konidia maka senyawa toxin yang dikeluarkan semakin banyak, begitu juga sebaliknya. Senyawa toxin yang dikeluarkan antara lain destruxin cytohalasins, swainsonine dan ditambah pula dengan adanya enzim kitinase dan protease. Patogen ini langsung mempenetrasi kedalam tubuh rayap dan kemudian berkecambah menutupi seluruh tubuh rayap, dan mampu menembus kutikula, serta dapat melisis kitin pada kutikula. Cendawan akan tumbuh dan berkembang pada rayap yang terinfeksi dan selanjutnya terjadi sporulasi.

Infeksi dimulai dengan penempelan konidia pada tubuh serangga, perkecambahan, penetrasi dan invasi serta kolonisasi dalam haemocoel, jaringan dan organ. Kelembapan yang tinggi pada sarang rayap sangat baik untuk pertumbuhan cendawan yang dapat menginfeksi rayap Robert et al., (1981) dalam 
Indria et al., (2013). Adanya interaksi fisik antar individu dalam koloni rayap, seperti kegiatan menyuapi (trophallaxis), memakan individu lain yang sakit atau malas (kanibalistik) dan bersentuhan (grooming), memungkinkan terjadinya penularan spora cendawan lebih cepat dari rayap yang terinfeksi dengan rayap yang sehat dalam koloni tersebut (Kramm et al., 1982 dalam Dwiastuti et al,. 2007).

\section{Persentase Penghambatan Makan Rayap C. curvignathus}

Hasil pengamatan terhadap persentase penghambat makan C. curvignathus dapat dilihat pada Tabel 4. Hasil analis ragam menunjukkan bahwa aplikasi cendawan $M$. brunneum berpengaruh sangat nyata terhadap persentase penghambatan makan $C$. Curvignathus..

Tabel 4. Rata-rata persentase penghambatan makan rayap C. curvignathus akibat aplikasi konsentrasi M. brunneum.

\begin{tabular}{cc}
\hline Kerapatan Konidia/mL Aquades & Penghambatan makan C. curvignathus \\
\hline K0 (kontrol) & $37,50 \mathrm{a}$ \\
K1 $\left(10^{2}\right)$ & $48,65 \mathrm{~b}$ \\
K2 $\left(10^{4}\right)$ & $49,23 \mathrm{~b}$ \\
K3 $\left(10^{6}\right)$ & $48,85 \mathrm{~b}$ \\
K4 $\left(10^{8}\right)$ & $47,69 \mathrm{~b}$ \\
K5 $\left(10^{10}\right)$ & $50,77 \mathrm{~b}$ \\
\hline BNT 0,05 & $\mathbf{4 , 1 6}$ \\
\hline
\end{tabular}

Tabel 4 menunjukkan bahwa rata-rata persentase penghambat makan $C$. curvignathus akibat aplikasi $M$. brunneum terdapat perbedaan nyata antara kontrol dengan perlakuan lain. Hal ini membuktikan bahwa isolat cendawan M. brunneum dapat mempengaruhi kinerja rayap baik terhadap kasta pekerja maupun kasta prajurit. Hal ini dikarenakan senyawa metabolik sekunder yang dikeluarkan oleh cendawan $M$. brunneum sangat berperan dalam menurunkan aktifitas rayap mencari makan sehingga berpengaruh terhadap kerusakan yang ditimbulkannya. Sesuai dengan pendapat (Adharini, 2008), yang menuyatakan bahwa jika makanan itu sesuai, rayap akan meneruskan makan, sebaliknya bila makanan itu

Coresponding author: revi_007@yahoo.com 
tidak memenuhi syarat rayap akan meninggalkan makanan yang disediakan dan memilih berpuasa. Dalam keadaan ini kondisi rayap akan lemah dan berangsurangsur mati atau sakit. Hal ini akan berpengaruh terhadap persentase penghambatan makan dari rayap tersebut. Efek penghambatan aktivitas makan dapat mengakibatkan serangga sasaran menjadi lemah dan perkembangan tertunda sehingga meningkatkan resiko diserang oleh musuh alami.

\section{KESIMPULAN}

Rata-rata viabilitas spora pada pengamatan 24, 30, dan 36 JSI berada diatas $80 \%$ sehingga sudah efektif untuk dijadikan biotermitisida. Mortalitas $C$. curvignathus tertinggi dijumpai pada aplikasi $10^{10}$ konidia/9 ml aquades dan $10^{6}$ konidia/9 ml aquades yaitu 100\%. Rata-rata keseluruhan perlakuan waktu kematian C. curvignathus akibat aplikasi cendawan M. brunneum mencapai $100 \%$ kurang dari 4 hari setelah aplikasi. Persentase penghambatan makan tertinggi dijumpai pada aplikasi $10^{10} \mathrm{konidia} / 9 \mathrm{ml}$ aquades yaitu $50,77 \%$.

\section{DAFTAR PUSTAKA}

Adharini, G. 2008. Uji Keampuhan Ekstrak Akar Tuba (Derris elliptica Benth) Untuk Pengendalian Rayap Tanah Coptotermes curvignathus Holmgren [skripsi]. Departemen Sulvikultur. Fakultas Kehutanan, Institut Pertanian Bogor.

Bustaman, S. 2007. Prospek dan Strategi Pengembangan Pala di Maluku. Balai Besar Pengkajian dan Pengembangan Teknologi Pertanian. Bogor.

Desyanti. 2007. Kajian Pengendalian Rayap Tanah Captotermes Spp. (Isoptera: Rhinotermitidae) dengan menggunakan Cendawan Entomopatogen Isolat Lokal [disertasi]. Bogor (ID): Fakultas Kehutanan, Insitut Pertanian Bogor.

Desyanti, Y.S. Hadi, T. Yusuf \& T. Santoso. 2007. Keefektifan beberapa spesies cendawan etomopatogen untuk mengendalikan rayap tanah Coptotermes gestroi WASMANN (Isoptera: Rhinotermitidae) dengan metode kontak dan umpan. J. Ilmu \& Teknologi Kayu Tropis 5(2): 68-77.

Dwiastuti, M.E, W. Nawir \& S. Wuryantini. 2007. Uji patogenisitas jamur entomopatogen Hirsutella citriformis, Beauveria bassiana dan Metarhizium spp. secara eka dan dwiinfeksi untuk mengendalikan Diaphorina citri Kuw. J. Hortikultura. Vol. 17 No. 1. Balai Penelitian Jeruk dan Buah Subtropika. Batu.

Coresponding author: revi_007@yahoo.com 
Faishol, A. 2011. Keefektifan Cendawan Metarhizium brunneum Petch Terhadap Hama Ubi Jalar Cylas formicarius Fabricius (Coleoptera: Brentidae). Bogor (ID). Fakultas Pertanian, Institut Pertanian Bogor.

Indria, S.P, S. Khotimah \& Rizalinda. 2013. Jenis-jenis jamur entomopatogen dalam usus rayap pekerja Coptotermes curvignathus Holmgren. Jurnal Protobiont. Vol 2 (3): $141-145$.

Nandika D, Y. Rismayadi \& F. Diba. 2003. Rayap: Biologi dan Pengendaliannya. Muhammadiyah University Press. Surakarta.

Prayogo, Y \& Suharsono. 2005. Optimalisasi pengendalian hama pengisap polong kedelai Riptortus linearis dengan cendawan entomopatogen Verticilium lecanii. J. Litbang Pertanian. 244.

Sayuthi, M. Hasanuddin, Husni \& Bakhtiar. 2013. Pemanfaatan Cendawan Entomopatogen Metarhizium brunneum Petch Untuk Pengendalian Hama Rayap Coptotermes curvignathus Holmgren (Isoptera:Termitidae) pada Tanaman Kopi. Laporan Tahunan Penetilitan Hibah Bersaing. Universitas Syiah Kuala, Aceh.

Trizelia. 2005. Cendawan Entomopatogen Beauveria bassiana (Bals.) Vuill. (Deuteromycotina: Hyphomycetes): keragaman genetik, karakterisasi fisiologis, dan virulensinya terhadap Croccidolomia pavonana (F.) (Lepidoptera: Pyralidae). Disertasi Sekolah Pascasarjana IPB. 